14

\title{
Неинвазивное измерение биоэлектрических потенциалов растений
}

\author{
() Т.Э. Кулешова, А.В. Бушлякова, Н.Р. Галль \\ Физико-технический институт им. А.Ф. Иоффе РАН, Санкт-Петербург, Россия \\ E-mail: www.piter.ru@bk.ru
}

Поступило в Редакцию 26 сентября 2018г.

В окончательной редакции 26 сентября 2018 r.

Принято к публикации 3 декабря 2018г.

\begin{abstract}
Разработана система неинвазивного измерения биоэлектрических потенциалов в системе почва-растение, основанная на новом не повреждающем растения способе обеспечения поверхностного контакта корневой системы с электродами, и проведено тестирование с использованием многолетнего травянистого растения Хлорофитум хохлатый. Показано, что полив растения сверху после выдержки в вододефицитном режиме вызывает скачок биопотенциала на уровне $200-250 \mathrm{mV}$ длительностью порядка $300 \mathrm{~s}$ с последующим выходом на плато, соответствующее физиологическому состоянию растения. В то же время диффузия воды снизу приводит к плавному изменению биоэлектрического потенциала с выходом на тот же уровень. Показано, что инвазивное введение электрода приводит к немонотонным и спадающим временни́м зависимостям биопотенциала, видимо являющимся ответом живой системы на повреждение.
\end{abstract}

DOI: 10.21883/PJTF.2019.05.47387.17541

Биоэлектрический потенциал (БЭП)- энергетическая характеристика взаимодействия и движения зарядов в исследуемой живой системе, которая измеряется как разность потенциалов между двумя точками ткани и отражает биоэлектрическую активность органа или организма в целом и характер протекания метаболических процессов.

БЭП живых организмов исследуются более 200 лет, но механизм их возникновения до сих пор не понят. Обычно считается, что причиной возникновения БЭП являются ионный транспорт минеральных элементов и циркуляция воды по проводящим сосудам растения. Известно, что ткани с высоким уровнем обмена веществ имеют отрицательный потенциал по отношению к более инертным, поврежденные ткани также имеют отрицательный потенциал относительно неповрежденных [1]. В большинстве случаев электрический потенциал почвы относительно растения отрицателен [2].

Перемещение ионов в разбавленных водных раствоpax внеклеточных и внутриклеточных жидкостей растений приводит к возникновению электрического тока. При этом подвижность иона определяется в первую очередь его молекулярным размером в гидратированной форме, а электрическое сопротивление связано с плотностью ионного потока [3].

Количество ионов в интерстициальных жидкостях растений напрямую зависит от метаболической активности тканей. Из-за различий в функционировании тканей и органов растений возникают градиенты БЭП, участвующие в перемещении веществ, регуляции процессов жизнедеятельности растений, электротонической передаче раздражений, морфогенетических процессах и др. [4,5]. Также изменение биоэлектрических потенциалов связано с внешними условиями роста растений: освещенностью, минеральным питанием, влажностью, температурой и т.д. [1,6].
Для измерения электрических явлений в тканях растений необходимо обеспечить омический контакт с тканями. Существует два различных способа измерения биоэлектрических потенциалов: 1) внутриклеточный потенциал фиксируется путем помещения рабочего электрода внутрь клетки, а референтного электрода - за ее пределами; 2) БЭП (часто называемый „активным потенциалом“) большой группы клеток, т.е. растительной ткани, определяется с помощью контакта электродов с разными точками растения, между которыми и проводится измерение [7-10].

Инвазивная установка электродов, сопряженная с повреждением тканей, может приводить к существенному изменению БЭП, которые в этой ситуации отражают не физиологические, а стрессовые процессы в организме [11]. Так, широко известные методы регистрации БЭП в теле человека - электрокардиография и электроэнцефалография, используемые для регистрации и исследования электрических процессов, протекающих при работе сердца и мозга, - базируются именно на установке неинвазивных электрических контактов.

Целью настоящей работы является разработка неповреждающего метода регистрации разности потенциалов, создаваемой растениями в ходе их жизнедеятельности.

В качестве объекта исследования были выбраны Хлорофитумы хохлатые (Chlorophytum comosum). К преимуществам данного растения следует отнести быстрый рост, размножение вегетативным способом, следствием которого являются получение большого количества образцов с идентичным генетическим кодом и отсутствие различия в наследственных признаках, а также развитая корневая система с большой площадью для контакта с электродами.

Для измерений БЭП растений использовались измерительные приборы с высоким входным сопротивлением, 


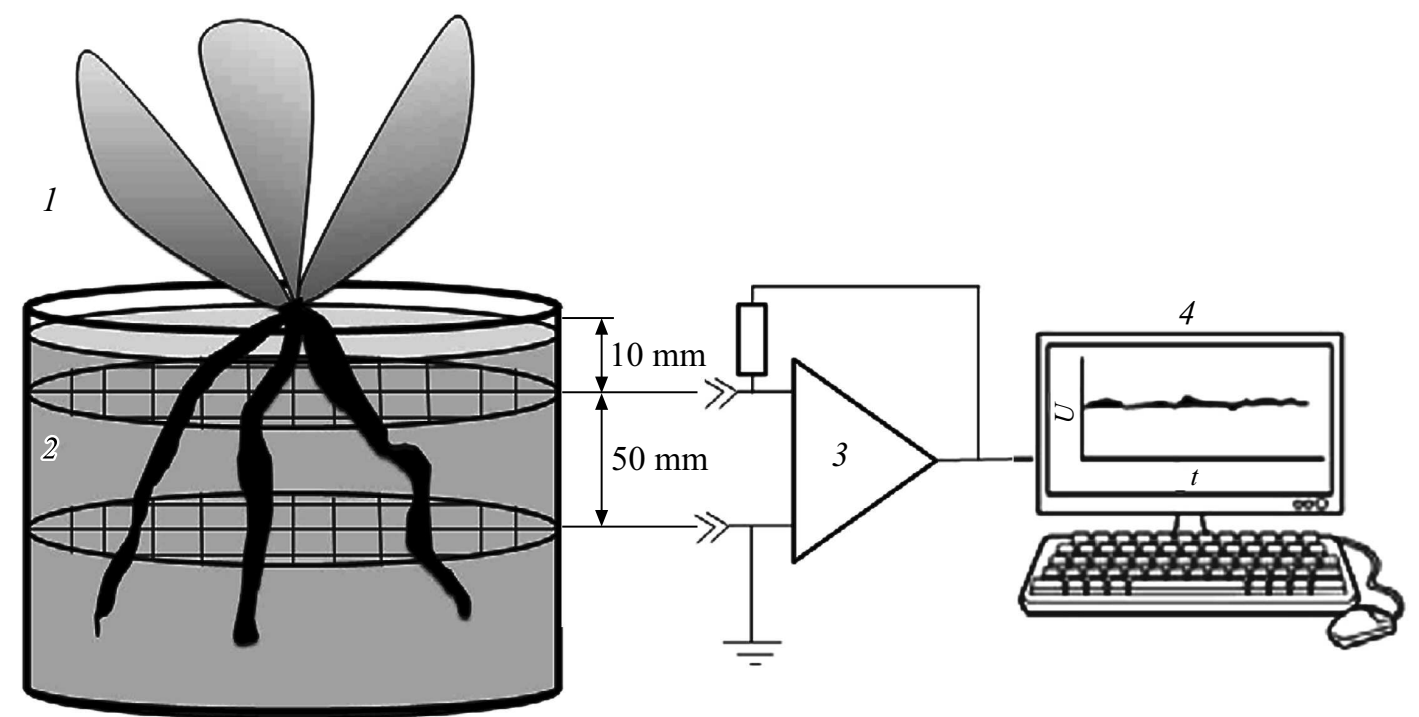

Рис. 1. Схема измерения биоэлектрического потенциала корней растения. 1 - исследуемый образец, 2 - электроды в виде сеток с выводами из емкости с субстратом, 3 - микроконтроллер, 4 - персональный компьютер.

превышающим внутреннее сопротивление живой ткани. Такой прибор слабо влияет на объект исследования, так как отбираемый им ток минимален и не вызывает поляризации ткани.

Серия экспериментов по измерению БЭП в листе хлорофитума относительно его корневой системы с использованием инвазивных контактов показала экспоненциальный спад сигнала от $70 \mathrm{mV}$ до 0 в течение $30 \mathrm{~min}$, а в ряде случаев наличие немонотонных временны́х зависимостей.

Для исключения возникновения эффектов, связанных с введением в живую ткань электродов и протеканием защитных реакций на рану, была разработана схема проведения эксперимента не повреждающим растение методом, что позволяет изучать электрофизиологический сигнал растительного организма непосредственно в условиях нормальной жизнедеятельности. В данном эксперименте применялся метод поверхностных неинвазивных измерений биоэлектрических потенциалов. Организация контакта выполнена с использованием двух проводящих сеток с размером ячейки $7 \times 7 \mathrm{~mm}$ из нержавеющей стали, которые помещаются на расстоянии $50 \mathrm{~mm}$ друг от друга в емкость объемом $500 \mathrm{ml}$, заполненную субстратом (рис. 1). Для автоматизации эксперимента и on-line мониторинга биоэлектрических потенциалов растений была использована платформа для разработки электронных устройств Arduino Mega 2560, базирующаяся на микроконтроллере ATmega 2560 и связанная с ПК через USB-кабель. Входное сопротивление устройства $100 \mathrm{k} \Omega$. Написанный на языке Arduino программный код (скетч) позволяет регистрировать и записывать разность потенциалов на электродных сетках раз в секунду или реже.

При отсутствии растения разности потенциалов между сетками зафиксировано не было, это позволило исключить предположение о возникновении контактных потенциалов. Сопротивление почвы в такой системе составило $0.5 \mathrm{M} \Omega$. При внесении в емкость $50 \mathrm{ml}$ воды сопротивление падает до $0.3 \mathrm{M} \Omega$, а при насыщении субстрата посредством добавления $150 \mathrm{ml}$ воды сопротивление почвы снижается до $0.12 \mathrm{M} \Omega$.

Для изучения влияния водного режима на изменение биоэлектрического потенциала растения был проведен эксперимент по измерению БЭП с течением времени в условиях варьируемой влажности почвы и организации градиентного распространения воды по направлению роста корней и против него. В емкость с электродными сетками был посажен хлорофитум, корни которого контролируемо пророщены сквозь сетки. Главное преимущество данной системы заключается в том, что корни растения физиологически касаются поверхности электродных сеток, образуя с ними электрический контакт, не вызванный каким-либо нарушением анатомического или физиологического состояния корней. Сопротивление в системе почва-растение составило $0.38 \mathrm{M} \Omega$.

В условиях достаточной влажности почвы биопотенциал менялся стохастически в интервале от 245 до $275 \mathrm{mV}$, при высыхании грунта значения падали в пределах 10\%. Первый полив от надземной части основания хлорофитума к корневой системе был осуществлен через 3 дня после начала эксперимента, последующие через 12 и 15 дней от последнего внесения воды. Во всех случаях вариации условий засухоустойчивости динамика изменения БЭП качественно схожая: наблюдается спад потенциала, затем увеличение и выравнивание до стационарного состояния. На рис. 2 приведена зависимость разности потенциалов между сетками в системе почва-растение от времени начиная с момента внесения в субстрат жидкости через 3 (кривая 2), 12 (кривая 1) и 15 дней (кривая 3) от предыдущего полива. 


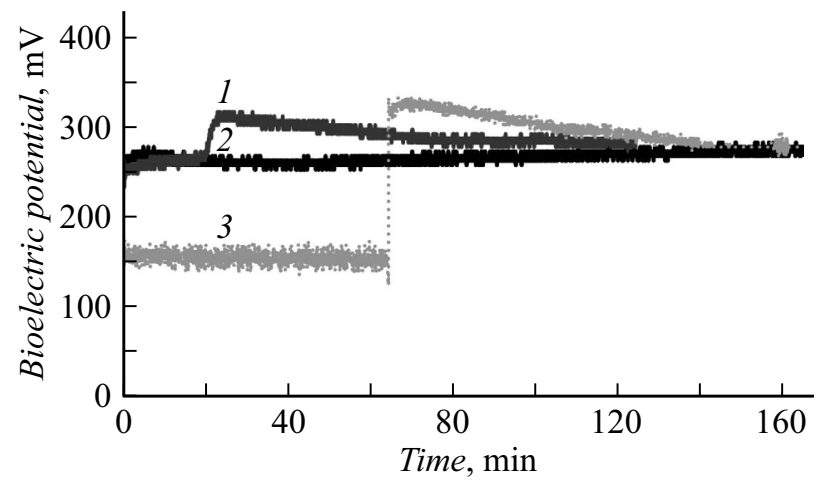

Рис. 2. Изменение биоэлектрического потенциала в момент увлажнения почвы от основания хлорофитума к корневой системе через 12 (1), 3 (2), 15 дней (3) с предыдущего полива.

Время задержки изменения потенциала после полива, характеризующее диффузионное распространение воды в почве, увеличивается с ростом периода без увлажнения почвы, причем диапазон изменения параметра составляет $\sim 20$ раз. Время нарастания БЭП до максимума, связанное с совокупностью процессов, включающих как физиологический ответ растения на увлажненность, так и чисто физический процесс шунтирования БЭП увлажненной почвой с повышенной проводимостью, наоборот, для всех экспериментальных условий оказывается близким. Время выхода БЭП на новый стабильный уровень, т.е. компенсационный эффект и адаптация растения, тоже зависит от того, сколько времени растение выдерживалось без полива. Если растение поливалось часто, то это время мало и составляет порядка $2.5 \mathrm{~min}$, при длительных интервалах между поливами оно может достигать 40-50 min.

Видно, что величина и, особенно, динамика изменений БЭП между почвой и растением зависят от меры засушливости почвы и степени вододефицитного стресса. При нормальных благоприятных условиях, когда растению хватает воды, биопотенциал стабилен. При нехватке воды потенциал начинает медленно падать, после полива происходит скачок потенциала, а также дальнейшее его увеличение и стабилизация.

Аналогично были проведены измерения для полива снизу - от конца корневой системы к основанию растения. Были сделаны три серии измерений с разным интервалом времени после полива: через 3, 12 и 15 дней от предыдущего увлажнения. При организации полива снизу не наблюдается скачка потенциала, а идет его плавное перераспределение, а также стабилизация за времена порядка десятков минут.

Разработанный метод неинвазивного мониторинга биопотенциалов корней растений в отличие от инвазивных методов позволил воспроизводимо наблюдать вариации БЭП в ответ на циклы увлажнения. Новый способ обеспечения контакта растение-электрод с помощью прорастания корней через электродные сетки является простым и относительно легко реализуемым, видимо, на широком круге растений. По сравнению с инвазивным методом он не вызывает физиологического ответа на рану, так как не вносит значительных изменений в жизнедеятельность растения, за счет того, что корни самопроизвольно прорастают сквозь металлические сетки.

Таким образом, с одной стороны, изменение биопотенциалов растений можно использовать как систему фитомониторинга, т.е. отслеживания состояний растительных организмов и стимуляции их развития, а с другой стороны, генерируемые при этом биотоки могут быть основой для создания технологии накопления и производства электроэнергии с помощью комбинации высших растений и микробных топливных элементов растительно-микробных топливных элементов, как это предлагалось в работах $[12,13]$.

\section{Список литературы}

[1] Коловский Р.А. Биоэлектрические потенциалы древесных растений. Новосибирск: Наука, 1980. $176 \mathrm{c}$.

[2] Поздняков А.И. // Почвоведение. 2013. № 7. С. 813-821.

[3] Tattar T.A., Blanchard R.O. // Annu. Rev. Phytopathol. 1976. V. 14. N 1. P. 309-325.

[4] Brenner E.D., Stahlberg R., Mancuso S., Vivanco J., Baluška F., Van Volkenburgh E. // Trends Plant Sci. 2006. V. 11. N 8. P. 413-419.

[5] Кутимская М.А., Бузунова М.Ю., Убрятова Л.В. // Вестн. ИрГСХА. 2014. № 60. С. 105-110.

[6] Hasegawa Y., Hoshino R., Uchida H. // Proc. of NOLTA. 2015. P. 860-863.

[7] Parkinson K.J. Bioelectric potentials in plants. Doctoral thesis. Durham University, 1963. $371 \mathrm{p}$.

[8] Karlsson L. // Rev. Sci. Instrum. 1972. V. 43. N 3. P. 458-464.

[9] Fromm J., Lautner S. // Plant Cell Environ. 2007. V. 30. N 3. P. 249-257.

[10] Ochiai T., Tago S., Hayashi M., Fujishima A. // ECS Transact. 2016. V. 75. N 16. P. 233-242.

[11] Tyler S.E.B. // Front. Physiol. 2017. V. 8. P. 627.

[12] Strik D.P., Hamelers H.V.M., Snel J.F., Buisman C.J. // Int. J. Energy Res. 2008. V. 32. N 9. P. 870-876.

[13] Moqsud M.A., Yoshitake J., Bushra Q.S., Hyodo M., Omine K., Strik D. // Waste Management. 2015. V. 36. P. 6369. 